\title{
Exploring knowledge and attitudes towards counselling about vitamin supplements in Jordanian community pharmacies
}

\author{
Received (first version): 7-May-2011
}

Accepted: 30-Nov-2011

\begin{abstract}
${ }^{*}$
The use of multivitamins within a pharmaceutical setting has been the subject of considerable debate. Objective: This research aimed to provide a platform for assessing and evaluating knowledge, attitudes and professional practices of Jordaninan community pharmacists in counselling patients about the safe consumption of vitamins.

Methods: A cross-sectional study was conducted between October 2009 and May 2010. Data collection was carried out using a 44-item semistructured self-administrated questionnaire. Setting: Community pharmacies in Amman with target sample of 400 pharmacists.

Results: A total of 388 pharmacists participated in this study. The majority $(77.8 \%)$ of pharmacists believed that a balanced diet is more achievable by eating healthily than by vitamins supplements. $78.1 \%$ of participants believed that vitamins deficiency would not shorten life spans, while $80.7 \%$ agreed that vitamin supplements could be toxic or might contain unlabelled harmful ingredients. Less than half of pharmacists were aware that some antioxidant vitamins have been verified to be of unproven value, or may even cause cancer. While over $80 \%$ of pharmacists would recommend vitamins on a regular basis without prescription, the majority agreed that counselling on vitamin supplements is part of their role in pharmaceutical care $(93.3 \%)$, in addition to providing relevant information to other healthcare professionals (78.4\%). Moreover, responses to specific knowledge questions, such as the interactions of vitamins with drugs or the recommended dietary allowance of vitamins for infants, children, and pregnant women, were negative. Furthermore, only a minority of pharmacists would recheck the accuracy of dose regimens in prescriptions and symptoms of true vitamins deficiency or would follow up patients to record any consequences of vitamins consumption.

Conclusion: The questionnaire revealed satisfactory awareness of community pharmacists about their role in counselling; however, further programmes to update their knowledge are mandatory to emphasise the importance of vitamin supplements as part of complementary medicine, and their exclusion from being considered as merely over the counter (OTC) products.
\end{abstract}

\footnotetext{
"Sireen A. SHILBAYEH. PhD. Associate Professor of Clinical Pharmacy. Pharmacy College, Princess Nora University . Riyadh (Saudi Arabia).
}

Keywords: Vitamins. Community Pharmacy Services. Professional Practice. Jordan.

\section{EXPLORANDO EL CONOCIMIENTO Y \\ ACTITUDES HACIA EL ASESORAMIENTO SOBRE SUPLEMENTOS VITAMÍNICOS EN FARMACIAS COMUNITARIAS JORDANAS}

\section{RESUMEN}

El uso de multivitamínicos en la Farmacia ha estado sujeto a considerable debate.

Objetivo: Esta investigación trato de proporcionar una plataforma evaluar el conocimiento, actitudes y práctica profesional de los farmacéuticos comunitarios de Jordania hacia el asesoramiento de pacientes sobre el consume seguro de vitaminas. Métodos: Se realizó un estudio transversal entre octubre 2009 y mayo 2010. La recogida de datos se hizo usando un cuestionario semi-estructurado y auto-administrado de 44 ítems. Entorno: Farmacias comunitarias de Amman, con un objetivo de muestreo de 400 farmacéuticos.

Resultados: Un total de 388 farmacéuticos participaron en el estudio. La mayoría de los farmacéuticos $(77,8 \%)$ creía que era más fácil conseguir una dieta equilibrada comiendo sano que con suplementos vitamínicos. El 78,1\% de los participantes creía que las deficiencias de vitaminas no acortarían los intervalos de vida, mientras que el $80,7 \%$ aceptó que los suplementos vitamínicos podrían ser tóxicos o podrían contener ingredientes no declarados peligrosos. Menos de la mitad de los farmacéuticos eran conocedores de que algunas vitaminas antioxidantes eran de valor no demostrado o podrían incluso producir cáncer. A su vez, más del $80 \%$ de los farmacéuticos recomendaría vitaminas de forma regular sin prescripción, la mayoría aceptó que el asesoramiento sobre suplementos vitamínicos es parte de su papel en cuidados farmacéuticos $(93,3 \%)$, además de proporcionar información relevante a otros profesionales de la salud $(78,4 \%)$. Las respuestas a preguntas específicas de conocimiento, tales como interacciones de las vitaminas con medicamentos, o las recomendaciones diarias de ingesta de vitaminas para bebés, niños y embarazadas, fueron negativas. Sólo una minoría de farmacéuticos verificaría la certeza de la dosis de regímenes prescritos y los síntomas de verdaderas deficiencias vitamínicas, o seguiría a los pacientes para registrar las consecuencias del consumo de vitaminas. Conclusión: El cuestionario reveló un conocimiento satisfactorio de los farmacéuticos 
comunitarios sobre su papel en asesoramiento; sin embargo, son necesarios nuevos programas para actualizar sus conocimientos y para enfatizar la importancia de los suplementos vitamínicos como parte de la medicina complementaria, y el abandono de considerar que son meramente productos OTC.

Palabras clave: Vitaminas. Servicios de farmacia comunitaria. Práctica profesional. Jordania.

\section{INTRODUCTION}

In the last two decades, there has been an increasing need for an expanded practice scope in community pharmacy. ${ }^{1,2}$ The most prominent factors driving this shift include increasing health demands associated with more complex ranges of chronic medicines, poor adherence to prescribed medicines $^{3}$, the recognition of drug-related morbidity and mortality leading to an increase in hospital admissions. As a result, the roles and responsibilities of professional pharmacists have evolved historically, from a focus on preparing and dispensing medication to extended pharmaceutical care services. In response to this change the American Pharmacists Association released a revised definition of pharmaceutical care as "a patient-centred, outcomes oriented pharmacy practice that requires the pharmacist to work in concert with the patient and the patient's other healthcare providers to promote health, to prevent disease, and to assess, monitor, initiate, and modify medication use to assure that drug therapy regimens are safe and effective". ${ }^{4}$ However, several practice-management barriers have prohibited the widespread application of pharmaceutical care practice in the community. These barriers include the pharmacy infrastructure and work flow of community pharmacies, the lack of imbursement for additional patient care services and the lack of specific pharmacist-patient care training. ${ }^{2}$ Nevertheless, patient counselling remains an integral service within the context of community orientated pharmaceutical care, particularly counselling on over the counter (OTC) products., Patient counselling is defined as "providing information orally or written form to the patient or his/her representative on direction of use, advice on side effect, precaution, storage, diet, and life style modification". Due to the increasing range of selfcare medicines and natural health products, the National Council on Patient Information and Education (NCPIE) has created the "Be MedWise" educational campaign to promote the safe and effective use of nonprescription drugs. ${ }^{8}$ This campaign builds upon the results of recent consumer survey, which demonstrated the risks of misuse of nonprescription drugs and dietary supplements by taking more than their recommended dosage, and potential interactions of non-prescription drugs with other concomitant prescription medications. ${ }^{9}$ Consequently, these issues have emphasised the importance of the role of pharmacists in offering evidence-based advice to ensure safe product selection and proper use. ${ }^{10-12}$ In addition, pharmacists must have the knowledge and experience to assist the decision making process of patients whenever self-medication is appropriate and when the expertise of another healthcare professional is desirable. ${ }^{11,12}$

\section{Complementary and alternative medicine and its relevance to vitamins}

While the definition of complementary and alternative medicine (CAM) (also termed unconventional, unorthodox, naturopathic, or integrative medicine) varies from country to country and continually changes over time ${ }^{13}$, it has been mostly defined as 'diagnosis, treatment and/or prevention which complements mainstream medicine by contributing to a common whole, satisfying a demand not met by orthodoxy, or diversifying the conceptual frameworks of medicine'. ${ }^{4-16}$ The National Council of Complementary and Alternative Medicine (NCCAM) created seven categories of CAM, including diet and nutrition therapies, which, for example, comprise vitamins therapies. ${ }^{16}$ In comparison, the American FDA defines dietary supplements according to the Dietary Supplement Health and Education Act (DSHEA) as a product that contains vitamins, minerals, herbals or other botanicals, or amino acids. ${ }^{17}$

\section{International and national rules and regulations}

Prior to 1994, the United States DSHEA exempted dietary supplements from FDA control. Since then, pharmacists have taken on the role of authenticating the ambiguous claims from supplement manufacturers, and offering effective counselling to their patients. ${ }^{10}$ Fortunately, in 1994 , Congress gave the FDA power to formulate manufacturing standards for dietary supplements. Today, the FDA has set premarket reviewing standards. These standards include testing for the purity, strength, and composition of all newly sold vitamins, herbs, and other dietary supplements or ingredients. $^{10}$ However, a disappointing pronouncement in a recent American survey stated that inadequately labelled and possibly confusing products were just as likely to be sold in pharmacies as other retail outlets. ${ }^{17}$ In addition, some of these products have been found to be contaminated with other herbs, pesticides, metals or unlabelled prescription drugs, such as digoxin. Furthermore, other products were found to contain less, more or zero amounts of the labelled ingredients. ${ }^{10,19}$ Therefore, it was recommended that consumers should not confuse the term "natural" product as a guarantee of safety, because these products are not regulated to a similar standard as prescription and nonprescription drugs. ${ }^{19,20}$

Jordan is a small developing Arab country, with a numerous economic problems such as debt, poverty, and unemployment. Before 1930, the pharmacy practice was mainly based on ethnopharmacological therapy, such as herbs. At present, pharmaceutical products are the third largest foreign currency earner for Jordan, of which several have been awarded Good Manufacturing Practices agreements certified from the European Union. Although 60 to $70 \%$ of the Jordanian 
population is insured, private community pharmacies are the most accessible primary health care facilities in country. To date, approximately 2073 registered community pharmacies are distributed across the country. Compared to developed countries, the Jordanian FDA's drug classifications and laws concerned with licensing, registration and marketing of various drug and food products are of equal standing. ${ }^{21}$ Herbal medicine regulations in Jordan were revised in 2001, to follow similar conventions as that of pharmaceutical medications, being categorized as Prescription, OTC and self-medication drugs. ${ }^{22}$ However, the application of such rules is not regularly scrutinised or strictly enforced in community pharmacies. Consequently, a patient may buy any medication without a prescription, excluding controlled narcotics and major tranquilizers. In addition, the wider public accessibility of vitamin and mineral products in nonpharmacy stores, and through multiple media sources, has augmented the potential for toxicity and increased interaction of supplements with other medications. In March 2008, the Jordanian Pharmaceutical Association (JPA) introduced the first Good Pharmacy Practice (GPP) project, which endeavours to establish a national association between independent community pharmacies in Jordan. The GPP was launched as an ambitious concept, which was conceived by a number of Jordanian pharmacists with a long-term vision and who are familiar with the continuous amendments evolving in the field of pharmacy practice in different countries around the world. Currently, the GPP Board in collaboration with other Jordanian governmental organisations works hard towards achieving its mission of applying the concept of pharmaceutical care and other international transformations that have a greater focus on patient health as a major concern, enforcing the role of the pharmacists in health care for the benefit and safety of patients. ${ }^{23}$

\section{Consumption by consumers}

Internationally, there has been a growing trend in the utilisation of CAM. ${ }^{15,24,25}$ This shift is due to growing cultural beliefs in the value of CAM towards improving health and in avoiding the uncomfortable side effects associated with conventional medications for chronic illnesses. ${ }^{26}$ Recent surveys revealed that 40 to $70 \%$ of individuals in the United States $^{6,24}$ and Canada ${ }^{11}$ consume multivitamins, herbs or mineral supplements on a daily or weekly basis. In the UK, $49 \%$ of general practices recommended access to some form of CAM in the year 2001 , compared to just $39 \%$ in $1995 .^{27}$ In stark contrast, a Jordanian study revealed that just $10 \%$ of participants reported using vitamins and minerals daily for different reasons (e.g. pregnancy, increased vitality or prevention of disease), while $15 \%$ stated that they use OTC herbal products on a daily basis. ${ }^{28}$

\section{Up to date knowledge concerning vitamin supplements}

It is well established among scientists that many diseases, subclinical conditions and symptoms are treated and controlled via the use of vitamins.
However, the concept that some multivitamins are beneficial, or are at least safe, remains controversial, particularly as contemporary research suggests that the potential risks far outweigh the benefits. $^{29-37}$ In 1991, The American National Institute of Health (NIH) established the Women's Health Initiative (WHI), which was a major 15-year research programme to address the most common causes of death, disability and poor quality of life in postmenopausal women, including cardiovascular disease, cancer and osteoporosis. ${ }^{38}$ A recent study involving 161,808 healthy postmenopausal women in the WHI programme revealed that those who used multivitamins had a similar potential for death or developing cardiovascular disease, cancer of the lung, colon/rectum, breast and/or endometrium, as those who did not consume vitamins. ${ }^{29}$ Consistent with these findings, other studies have demonstrated weak evidence to support the approval of multivitamins as antioxidant protection against cardiovascular disease ${ }^{30,31}$ or cancers. ${ }^{32,33}$ Further evidence was drawn from a Cochrane Collaboration review of randomised trials of antioxidant supplements for primary and secondary prevention, which showed higher death rates among people who were assigned to supplements of vitamin $A$, vitamin $E$ and beta carotene. ${ }^{34}$ Moreover, several multivitamins contain excess quantities of micronutrients compared to those specified by the Recommended Dietary Allowance (RDA) ${ }^{29,30}$ Therefore, individuals consuming these supplements together with their healthy diet may easily exceed the tolerable upper intake limits. ${ }^{35,36}$ Collectively, these findings support the American Heart Association (AHA) recommendations of a balanced diet, with emphasis on antioxidant-rich fruits, vegetables and whole grains, rather than supplements of questionable benefits and safety ${ }^{37}$, particularly in patients without chronic health conditions or circumstances requiring vitamin replacement.

There have been numerous research studies worldwide on CAM. Typically, the aims of these studies were to describe the attitudes of pharmaceutical students, faculties, and professionals towards, the beliefs and perceptions about CAM. ${ }^{11,15,25,39-43}$ The outcomes of these surveys demonstrated that pharmacy professionals appraise their knowledge of CAM as insufficient, and are insecure in answering patient enquiries. ${ }^{41}$ However, there is currently little qualitative research exploring the perspectives of pharmacists on multivitamins as a subcategory of CAM, and the justifications supporting their views. To our knowledge, only two published Jordanian studies have been conducted on societal perspectives of self-medication and OTC global use. ${ }^{28,44}$ Therefore, this is the first Jordanian survey to explore the perceptions of community pharmacists on their role in counselling and pharmaceutical care services.

This project aimed to assess the awareness of community pharmacists in Jordan towards recent vitamin related efficacy and safety issues and to evaluate their attitudes and professional practice behaviour in counselling patients about vitamin supplements. 


\section{METHODS}

Between October 2009 and May 2010, a crosssectional descriptive-design study was conducted in pharmacies located in Amman, the capital city of Jordan,. The sampling frame was defined as any registered or qualified pharmacists who work in community pharmacies. Pharmacists were randomly selected from different geographical locations; with a target sample of 400 pharmacists from 400 different pharmacies (this corresponds to $34 \%$ of the total 1180 registered community pharmacies within Amman). One pharmacist on duty from each visited pharmacy was invited to participate in the survey. Data collection was carried out using a semi-structured self-administrated questionnaire. The questionnaire design was centred on the most recent evidence-based information about vitamins, and was intended to examine the frequency of dispensing vitamin supplements based on proper counselling practice in Pharmaceutical Care. ${ }^{7}$ Pilot testing was carried out with 20 pharmacists at 10 community pharmacies to examine the clarity of items, and acceptability of questionnaire length. The results of the pilot study were not included in the statistical analysis of the study. The questionnaire was written and conducted in English, which is the primary language of pharmacy colleges in Jordan. The final form of the questionnaire comprised 44 questions with two types of responses: free-text replies and pre-stratified choices. The questionnaire form was divided into five sections: (a) demographic data (e.g. age, gender, education level, and years of practice); (b) recently published general evidencebased research concerning multivitamins; (c) signs and symptoms of individual vitamin deficiency, underuse and overuse of vitamin supplements; (d) awareness about various vitamins supplements doses compared to RDA, side effects, drug interactions and contraindications; and (e) natural and dietary source of vitamins. For the purpose of our analysis, the questions were reclassified into one of the following categories: (a) basic knowledge; (b) advanced knowledge (recent literature); (c) professional practice behaviours; and (d) attitudes and beliefs towards pharmaceutical care services.

All data were coded, entered and analysed using the Statistical Package for Social Sciences (SPSS) (version 17.0; SPSS Inc., Chicago, IL). The responses of the pharmacists to each questionnaire item were expressed as frequencies and their corresponding percentages. The total score for each question category was estimated by calculating the mean and standard deviation of the responses from each subgroup. The overall score out of $100 \%$ was rated as unsatisfactory $(<50 \%)$, satisfactory $(50-60 \%)$, good $(>60-<70 \%)$, very good $(70-<80 \%)$, or excellent (80-90\%) knowledge. Moreover, mean or individual scores above $70 \%$ in the behaviour or attitude questions were considered to reflect more positive trends towards the statements.

\section{RESULTS}

\section{Demographics}

Of the total 400 questionnaires, only 12 (3\%) were returned unusable, giving a response rate of $97 \%$. With respect to gender, $51.8 \%$ were men while $48.2 \%$ were women. The median age was 29 years (range: 21-48), with the predominant age group being between 20 and 29 years of age, followed by 30 to 39 years. With respect to education levels in pharmaceutical practice, the principal group was Bachelor of Science in pharmacy $(82.9 \%)$. As shown in Table 1, the pharmacists who participated in this study had a wide range of experience in practice, ranging from less than a year up to 37 years.

\begin{tabular}{|c|c|}
\hline Characteristics & Respondents ( \%) \\
\hline $\begin{array}{r}\text { Male } \\
\text { Female }\end{array}$ & $\begin{array}{l}201(51.8) \\
187(48.2)\end{array}$ \\
\hline $\begin{array}{l}20-29 \text { years old } \\
30-39 \text { years old } \\
40-49 \text { years old }\end{array}$ & $\begin{array}{c}181(46.7) \\
158(40.7) \\
49(12.6) \\
\end{array}$ \\
\hline $\begin{array}{r}\text { Level of education } \\
\text { Diploma in pharmacy } \\
\text { Bachelor of science in pharmacy } \\
\text { Master of science in pharmacy } \\
\text { Doctor of pharmacy }\end{array}$ & $\begin{array}{c}50(12.9) \\
322(82.9) \\
8(2.1) \\
8(2.1) \\
\end{array}$ \\
\hline $\begin{array}{r}<1 \\
1-5 \\
6-10 \\
11-15 \\
16-20 \\
>20\end{array}$ & $\begin{array}{c}73(18.8) \\
157(40.5) \\
92(23.7) \\
34(8.8) \\
17(4.4) \\
15(3.9)\end{array}$ \\
\hline
\end{tabular}

\section{General and up to date knowledge about} vitamins

Table 2 presents the results of basic and advanced knowledge assessments for the first group of survey questions.

The majority $(77.8 \%)$ of the pharmacists believed that a balanced diet is more achievable by eating healthily than by supplementing with vitamins. In parallel, $72.4 \%$ acknowledged that the dose consistency of vitamins may be significantly decreased by the abuse of plant pesticides, while $79.6 \%$ agreed that natural vitamins are processed differently in the body compared to those obtained from synthetic sources.

Of note, $78.1 \%$ of participants were not aware that the chronic consumption of certain vitamins has been proven to shorten the human life span; however, $80.7 \%$ agreed that vitamin supplements could be toxic or contain unlabelled harmful ingredients. Strikingly, less than half $(33.8 \%)$ of pharmacists were aware that a number of antioxidant vitamins have been verified as having no health benefits or may even cause cancer. However, the majority (96.9\%) agreed that some life style related factors may cause the depletion or reduce the absorption of vitamins, such as high dietary fat intake $(67.7 \%)$, low fruit and vegetable intake $(91 \%)$, regular use of NSAIDs $(58.5 \%)$, low 


\begin{tabular}{|c|c|c|c|}
\hline Statement (correct answer) & Correct & Incorrect & $\begin{array}{l}\text { I don't know } \\
\text { (missing data) }\end{array}$ \\
\hline $\begin{array}{l}\text { Total balanced diet is more achievable by eating healthily than by multivitamin } \\
\text { supplements (true) }\end{array}$ & $302(77.8)$ & $86(22.2)$ & $0(0)$ \\
\hline $\begin{array}{l}\text { The dose consistency of vitamins is significantly decreased by the abuse of } \\
\text { plant pesticides (true) }\end{array}$ & $281(72.4)$ & 104(26.8) & $3(0.8)$ \\
\hline Vitamins supplements may contain unlabelled toxic ingredients (true) & $313(80.7)$ & $73(18.8)$ & $2(0.5)$ \\
\hline $\begin{array}{l}\text { Chronic consumption of certain vitamins has been proven to shorten lifespan } \\
\text { (true) }\end{array}$ & $81(20.9)$ & $303(78.1)$ & $4(1)$ \\
\hline $\begin{array}{l}\text { A growing body of research evidence supports the causality of different types of } \\
\text { cancer by multivitamins, which are often employed as antioxidants in routine } \\
\text { practice (true) }\end{array}$ & $131(33.8)$ & $252(64.9)$ & $5(1.3)$ \\
\hline $\begin{array}{l}\text { Natural vitamins are processed differently in the body from those obtained from } \\
\text { synthetic resources (true) }\end{array}$ & $309(79.6)$ & $78(20.1)$ & $1(0.3)$ \\
\hline A proportion of up to $90 \%$ of a vitamin supplement may be lost in faeces (true) & $132(34)$ & $256(66)$ & $0(0)$ \\
\hline $\begin{array}{l}\text { Some lifestyle issues may reduce the absorption of vitamins or may even cause } \\
\text { the complete depletion of vitamins (true) }\end{array}$ & $376(96.9)$ & $11(2.8)$ & $1(0.3)$ \\
\hline $\begin{array}{l}\text { Chronic consumption of some drugs may cause a significant depletion of } \\
\text { vitamins (true) }\end{array}$ & $298(76.8)$ & $87(22.4)$ & $3(0.8)$ \\
\hline $\begin{array}{l}\text { Serious drug interactions and side effects can be potentiated due to } \\
\text { concomitant consumption of vitamin supplements and drug therapy (true) }\end{array}$ & $289(74.5)$ & $94(24.2)$ & $5(1.3)$ \\
\hline $\begin{array}{l}\text { Knowledge of exact RDA for each vitamin (according to the respondent self- } \\
\text { assessments) }\end{array}$ & $179(46.1)$ & $209(53.9)$ & $0(0)$ \\
\hline $\begin{array}{l}\text { Knowledge of specific signs and symptoms of each vitamin deficiency } \\
\text { (according to the respondent self-assessment) }\end{array}$ & $260(67)$ & $121(31.2)$ & $7(1.8)$ \\
\hline Mean score (SD) $[95 \% \mathrm{Cl}]$ & \multicolumn{3}{|c|}{$63.4(23.7)[48.4-78.4]$} \\
\hline
\end{tabular}

physical activity $(69.6 \%)$ and/or smoking (92\%). Of the total 298 pharmacists (76.8\%) who agreed with the statement that drugs induce vitamin depletion, only 171 provided the names and categories of such medications. The top five medications cited by pharmacists were diabetic medications $(n=14)$, NSAIDs $(n=7)$, salicylates $(n=6)$, hormones $(n=6)$ and antibiotics $(n=6)$. Likewise, out of 289 pharmacists $(74.5 \%)$ who agreed on the potential of serious negative interactions between vitamins and other drugs, only a few $(n=61,21.1 \%)$ were able to provide names, including contraceptives $(n=18)$, neomycin $(n=8)$, antiplatelets $(n=4)$, warfarin $(n=2)$ and tetracyclines $(n=1)$. In contrast, 94 pharmacists $(24.2 \%)$ did not agree on the validity of such interactions with supplements. According to the respondent self-assessment, $67 \%$ of pharmacists felt they had sufficient information about the manifestations of vitamin deficiency. In comparison, more than half of the survey respondents (53.9\%) declared that they had limited knowledge on the Dietary Reference Values for vitamins. Therefore, their responses to subsequent specific knowledge questions, such as the RDA of vitamins for infants, children, pregnant and lactating women, were negative.

With regard to pharmaceutical manufacturing knowledge, only $34 \%$ of pharmacists declared awareness of a potential of up to $90 \%$ loss of vitamin supplement content in faeces due to poor bioavailability.

Collectively, the average score of all respondents in the knowledge assessment was $63.4 \% \pm 23.7$ (95\% $\mathrm{Cl}$ : 48.4-78.4), which is rated as good knowledge, with only $81(20.9 \%)$ pharmacists answering all questions correctly.

Table 3. Counselling behaviours of pharmacists with respect to vitamin supplements $(n=388)$

\begin{tabular}{|c|c|c|}
\hline Statement & $\begin{array}{l}\text { Agree } \\
\mathrm{N}(\%)\end{array}$ & $\begin{array}{l}\text { Disagree } \\
\mathrm{N}(\%)\end{array}$ \\
\hline $\begin{array}{l}\text { I often verify the indications of vitamins for prophylactic or therapeutic purposes if prescription is } \\
\text { available }\end{array}$ & $277(71.4)$ & $111(28.6)$ \\
\hline I recommend vitamin supplements very often and even without prescription & $309(79.6)$ & $79(20.4)$ \\
\hline I usually evaluate potential drug interactions with concomitant medications & $235(60.6)$ & $153(39.4)$ \\
\hline I counsel the patient/ consumer about the side effects of megavitamins consumption in large doses & $289(74.5)$ & $99(25.3)$ \\
\hline I review the patient profile to rule out contraindications of vitamin supplements & $292(75.3)$ & $96(24.7)$ \\
\hline $\begin{array}{l}\text { I regularly consult references covering all RDA for infants, children, male, female, pregnant and } \\
\text { lactating women, the elderly, in addition to renal and other chronic diseases }\end{array}$ & $238(61.3)$ & $150(38.7)$ \\
\hline I routinely recheck the prescribed dose according to specific RDA before dispensing a prescription & $195(50.3)$ & $193(49.7)$ \\
\hline $\begin{array}{l}\text { I would like to ask consumers questions to re-evaluate the signs and symptoms of vitamin deficiency } \\
\text { to to ensure correct vitamin supplement choice }\end{array}$ & $205(52.8)$ & $183(47.2)$ \\
\hline $\begin{array}{l}\text { I am keen to follow up the patients who are continually using vitamins to record any bad or beneficial } \\
\text { effects }\end{array}$ & $217(55.9)$ & $171(44.1)$ \\
\hline I counsel the patient/consumer about the significance of natural sources of vitamin & $272(70.1)$ & $116(30)$ \\
\hline I remind the patient/consumer to read specific usage instructions & $325(83.8)$ & $63(16.2)$ \\
\hline $\begin{array}{r}\text { I counsel the patient/consumer about several essential lifestyle issues such as: } \\
\text { Adjusting food content and quantities to avoid vitamin toxicity } \\
\text { Proper storage and cooking of fruits and vegetables } \\
\text { Daily requirements of water } \\
\text { Cessation of smoking }\end{array}$ & $\begin{array}{l}257(66.2) \\
261(67.3) \\
233(60) \\
240(61.9)\end{array}$ & $\begin{array}{l}131(33.8) \\
127(32.7) \\
155(40) \\
148(38.1)\end{array}$ \\
\hline Mean score (SD) [95\%Cl] & \multicolumn{2}{|c|}{$66.1(9.8)[60.7-71.5]$} \\
\hline
\end{tabular}




\begin{tabular}{|c|c|c|c|c|c|}
\hline Children & $118(38.1 \%)$ & $28(9 \%)$ & $3(1 \%)$ & $2(0.8 \%)$ & $5(1.6 \%)$ \\
\hline Elderly & $102(33.2 \%)$ & $21(6.7 \%)$ & $0(0 \%)$ & $9(2.8 \%)$ & $84(27.2 \%)$ \\
\hline Pregnant or Lactating women & $115(37.4 \%)$ & $14(4.6 \%)$ & $2(0.8 \%)$ & $0(0 \%)$ & $2(0.8 \%)$ \\
\hline Patients with Chronic Diseases & $80(26 \%)$ & $14(4.4 \%)$ & $49(15.7 \%)$ & $4(1.3 \%)$ & $34(11.1 \%)$ \\
\hline
\end{tabular}

Professional practice behaviour of pharmacists with respect to dispensing and counselling about vitamin supplements

Table 3 shows the results of the pharmacist counselling and dispensing behaviours evaluated in this study. The pharmacists obtained a mean score of 66.1 (SD=9.8)\% (95\%Cl: 60.7 to 71.5$)$, which may be considered representative of a moderately positive behavioural attitude with respect to counselling patients about vitamins. In general, the majority of pharmacists declared their adherence to several counselling items, in accordance with good pharmaceutical care practice ${ }^{7}$, namely indications $(71.4 \%)$, interactions $(60.6 \%)$, side effects of megavitamins consumption in large doses (74.5\%), contraindications (75.3\%), usage instructions $(83.8 \%)$ and essential life style issues (>60\%).

While $79.6 \%$ of pharmacists agreed on recommending vitamin supplements regularly and even without prescription, only $50.3 \%$ would recheck for the accuracy of dose regimens in prescriptions according to specific age or patient category RDA. In parallel, $52.8 \%$ may confirm the true signs and symptoms of vitamin deficiencies by initiating an open dialogue with the patient or his/her family. Furthermore, $58.6 \%$ would follow up the patient to record any positive or negative effects based on their choice of vitamin supplements. Respondents were asked to estimate the frequency of the most regularly dispensed vitamin products in their pharmacies. The pharmacists responses arranged according to frequency were as follows: multivitamins $(n=337,86.9 \%)$, vitamin C $(n=248$, $63.9 \%)$, vitamin $E(n=155,39.9 \%)$, fish oil $(n=122$, $31.4 \%)$, and vitamin $A(n=114,29.4 \%)$. In addition, pharmacists were asked to rate the frequency of choosing different vitamins for each patient subgroup (the data is summarised in Table 4). The dispensing of multivitamins was significantly higher than other type of vitamins (ANOVA P-value $<0.001$ ). In contrast, the pattern of dispensing vitamin supplements displayed no significant variation across different patient subgroups ( $P$-value Chi-square $>0.05$ ).

Approximately $60 \%$ of pharmacists stated that they noticed variable efficacy for different brand products of the same vitamins. In this regard, pharmacists mostly attributed their impression as being based on the variability in cost, patient compliance and/or the number of requests for specific products, rather than their professional monitoring of subjective and objective parameters.

As shown in Table 3, $71.4 \%$ of pharmacists declared that they verify the indications of vitamins for prophylactic or therapeutic purposes if a prescription is available, while $83.5 \%$ stated that they would also recommend vitamins very often, even without prescription. The most frequently cited clinical conditions in which vitamins would be recommended as an OTC medicines were hair and nail loss, pregnancy, heavy smoking, loss of appetite and elderly related complaints. Lactation, prophylactic antioxidant and general malaise were among the less common indications. Other rare conditions are presented in Table 5.

\begin{tabular}{|c|c|}
\hline \multicolumn{2}{|c|}{$\begin{array}{l}\text { Table 5. Clinical conditions cited by pharmacists for } \\
\text { dispensing vitamin supplements as OTC medicines } \\
(\mathrm{n}=274) \text {. }\end{array}$} \\
\hline Clinical Conditions & Frequency (\%) \\
\hline Hair and Nail loss & $26(9.5)$ \\
\hline Pregnancy & $25(9.1)$ \\
\hline Heavy Smoking & $17(6.2)$ \\
\hline Loss of Appetite & $17(6.2)$ \\
\hline Elderly condition & $17(6.2)$ \\
\hline Lactation & $10(3.7)$ \\
\hline General Malaise & $4(1.5)$ \\
\hline Prophylactic antioxidant & $4(1.5)$ \\
\hline Weight gain & $3(1.1)$ \\
\hline Cold & $3(1.1)$ \\
\hline Diabetes & $3(1.1)$ \\
\hline URTI/UTI & $3(1.1)$ \\
\hline Anaemia & $2(0.7)$ \\
\hline Hypertension & $2(0.7)$ \\
\hline Reducing cholesterol & $2(0.7)$ \\
\hline Increasing immunity & $2(0.7)$ \\
\hline Miscellaneous* & $134(48.9)$ \\
\hline $\begin{array}{l}\text { URTI, upper respiratory } \\
\text { tract infection; } \\
{ }^{*} \text {, unspecified patient/ cor }\end{array}$ & $\begin{array}{l}\text { ns; UTI, urinar } \\
\text { sts. }\end{array}$ \\
\hline
\end{tabular}

Table 6. Reasons reported by pharmacists who responded positively to counselling patients about natural sources of vitamins $(\mathrm{n}=272)$

\begin{tabular}{|l|c|}
\hline Reasons & Frequency (\%) \\
\hline Natural sources are safer & $123(45.5)$ \\
\hline Are better for general health & $44(16.2)$ \\
\hline $\begin{array}{l}\text { It is important to benefit initially } \\
\text { from routine meals }\end{array}$ & $57(21.0)$ \\
\hline $\begin{array}{l}\text { Less expensive than synthetic } \\
\text { products }\end{array}$ & $28(10.3)$ \\
\hline $\begin{array}{l}\text { To prevent over dosage of certain } \\
\text { vitamins }\end{array}$ & $19(7.0)$ \\
\hline
\end{tabular}

Over half of the pharmacists $(70.1 \%)$ believed that it is important to counsel patients about natural sources of vitamins. The main reason for counselling about natural food sources of vitamins was cited as "natural sources are safer" $(45.5 \%)$, as shown in Table 6 . Out of the total 272 pharmacists who recommended natural sources, $21 \%$ believed that it is essential to benefit from balanced meals and $16.2 \%$ believed that it is better for general health. In comparison, $10.3 \%$ of pharmacists believed that natural sources are less expensive, while only $7 \%$ were concerned about over dosage as a result of repeated vitamin supplementation combined with daily food intake. 


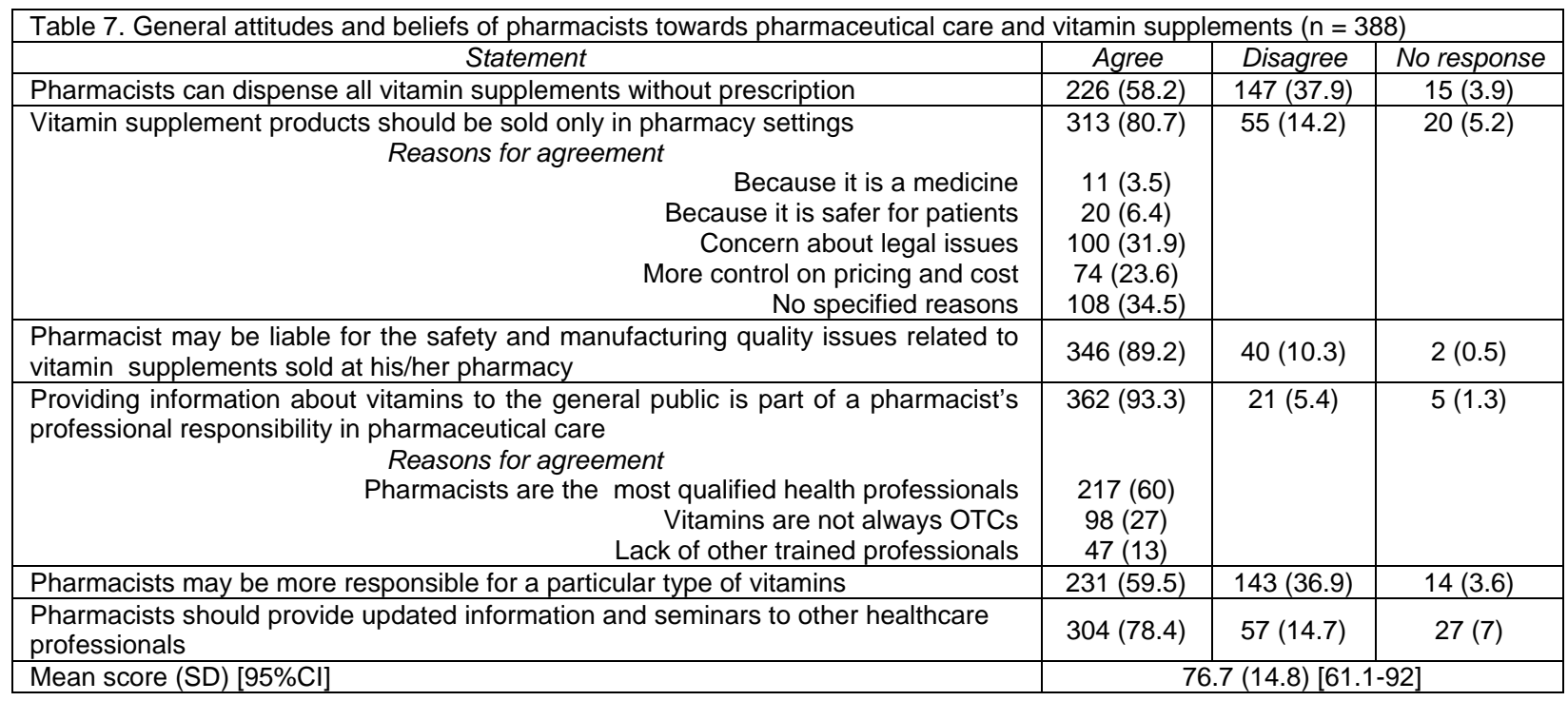

\section{Sources of information}

When pharmacists were asked about additional globally available information sources relating to vitamin product guidance, many pharmacists referred to leaflets/package inserts (40\%), sales promoters $(25 \%)$ and/or unspecified sites on the Internet (16\%). A few pharmacists would consult the British National Formulary (10\%), United States Pharmacopeia (5\%), British Pharmacopeia (3\%) and/or other sources (2.8\%), such as seminars, patients, doctors or their undergraduate education. Surprisingly, none of the respondents were aware of the more specialised and regularly updated Internet sites that have been created by the FDA or NCCAM, and which contain all the currently recommended Dietary Reference Values for vitamins.

\section{Perceived education and training}

When asked about previous education covering vitamins and their bioavailability, only $25 \%$ of pharmacists believed they had sufficient education in undergraduate courses $(10 \%)$ or through vitamin company seminars that they have attended during their pharmacy practice (15\%). Interestingly, $71.1 \%$ thought they had received very limited education, and $3.9 \%$ declared they had only learned through their own experience. None of the pharmacists indicated that they had received any guidelines on vitamins or dietary supplements during the required training period before their graduation and subsequent registration in the JPA.

\section{General attitudes towards and beliefs about pharmaceutical care regarding vitamin supplements}

In general, pharmacists displayed positive trends in their beliefs and perceived concepts towards pharmaceutical care and vitamin supplements (mean score, 76.7, SD=14.8; Median 79.5; 95\%Cl: $61.1-92) .58 .2 \%$ of pharmacists indicated that they would dispense all vitamins without prescription. The majority of pharmacists believed that counselling on vitamin supplements is part of their role in pharmaceutical care (93.3\%), and that pharmacists should provide updated information about vitamin products to other members of the health care team $(78.4 \%)$. The reasons for the former statement are summarised in Table 7.

With respect to rating the most professional experts in prescribing vitamins, $86 \%$ of participants selected the pharmacist, $58.4 \%$ selected the physician, $58.1 \%$ selected the dietician and only $8.5 \%$ selected the naturopath.

\section{DISCUSSION}

This study is the first survey to be conducted in Jordan under community pharmacy settings, with the main objectives being to explore the knowledge, awareness and attitudes of pharmacists towards counselling about vitamin supplements, which are becoming the most common OTC items worldwide. $6,11,15,24,25,28$

This study has showed that, although pharmacists displayed satisfactory basic knowledge, very few pharmacists were aware that researchers are thinking more cautiously about recommendations regarding multivitamin usage under certain conditions, based on considerable research in the past ten years. ${ }^{29-37}$ In fact, more than two-thirds of participants were not informed that the chronic consumption of certain vitamins has been proven to shorten the human life span, and that some vitamins may cause cancer. These findings may be ascribed to a lack of continuing professional development, and/or generally less interest in updating knowledge about "medicines without prescription" than prescribed ones. ${ }^{2,3,5}$ Moreover, pharmacists' scores in perceived knowledge of vitamins' drug interactions, side effects and depletion with concomitant prescribed medication was high $(>70 \%)$. However, yet their actual knowledge base was modest, as only a small percentage were likely to enumerate examples. Similar results were obtained from pharmacists in Kuwait, who seemed to be more educated about the uses of herbal products, and less informed about their side effects and interactions. ${ }^{45}$ These results are not surprising in the current sample, since only 
$10 \%$ declared to have received a fair education during their undergraduate studies about vitamins.

Evidently, most respondents in the current survey were not aware about the potential differences in the bioavailability achieved from various vitamin products, and the possibility of up to $90 \%$ loss in faeces due to poor manufacturing quality. Actually, only $34 \%$ of pharmacists agreed on the acknowledgement of such a statement. A possible explanation for this is the conceptual belief that dietary supplements, including vitamins, are exempted $^{10}$ from many bioequivalence regulations worldwide, and consequently the laws in Jordan in this area are still unresolved. In contrast, many pharmacists agreed that the sale of such products should be confined to pharmacy settings, and pharmacists may be legally liable to their safety and quality standards despite oversights in current regulations. This was also reported by Canadian pharmacists, who felt that approval for the sale of natural or dietary supplements should be granted by Health Canada, based on numerous stratums of evidence relating to safety and efficacy, particularly due to their perceived lack of governmental regulation. $^{46}$

Fortunately, the current survey data indicated that Jordanian pharmacists ( $>70 \%$ ) were conscious of their professional role in patient counselling, namely proper indications, usage instructions, contraindications, significance of natural vitamin sources and the potential adverse effects of megavitamin consumption. However, they were less likely $(<70 \%)$ to provide advice on potential interactions with concomitant medications. Similar findings were obtained in previous studies in which pharmacists reported that they never or rarely asked their patients about the concomitant use of CAM or herbal remedies. ${ }^{42,45,47,48}$ Another gap in the counselling skills of pharmacists was identified when more than half of participants admitted to not routinely rechecking vitamin prescriptions for correct dosage regimens in accordance with specified RDA values for various ages, gender, life events (such as pregnancy) and clinical conditions (such as renal disease). This would explain their negative attitudes toward reviewing references that are periodically updated to cover all RDA values. Again, this was reflected in their poor responses to specific RDA inquiries in the survey questionnaire. This was further clarified when pharmacists were asked to illustrate their sources of information in counselling, with the majority relying on easy to access references. Thus, it is clear that there is a perceived lack of quality information and/or access to it. Therefore, further efforts must be implemented to orient the pharmacist to more reliable resources on vitamin products, such as publications by NCCAM and the NIH Office of Dietary Supplements (ODS), as well as other Federal agencies. ${ }^{20,29}$

Based on the current state of knowledge and evidence-based literature concerning multivitamins, it is essential that pharmacists, being the most accessible healthcare members, routinely establish an open dialogue with their customers to ensure a clear distinction between harmful and useful CAM therapies, including vitamins and any other nonprescribed medications. A previous Jordanian public survey ${ }^{44}$ illustrated high societal perspectives on the role of community pharmacists, whereby $66.4 \%$ of participants reported always or often visiting the same pharmacy, with $20.9 \%$ of them citing the provision of good advice as being the main reason. Moreover, $62.7 \%$ of patients would consult a pharmacist rather than a doctor on minor conditions to select the proper choice of OTC products. However, in the current survey, $58.6 \%$ of pharmacists stated that they would follow up patients to record any effects of these products. These findings seem to be promising for the future implementation of pharmaceutical care services in Jordan, particularly if our pioneer GPP board ${ }^{23}$ succeeds in achieving their goal of promoting standards for ethical and professional practices of the pharmacy profession that, once implemented by more community pharmacists, are intended to have positive effects on the image of pharmacists in society.

It is interesting to note the high response rate by pharmacists in this study. This could be attributed to a number of factors including; (a) a remarkably positive attitude by Jordanian pharmacists towards pharmaceutical care and its professional career prospects, (b) an increase in consumer demand for vitamin, herbal and dietary products as a result of more assertive advertising and marketing campaigns, (c) that this is a pioneering study within Jordan and generated considerable interest and/ or (d) a committed research team who were extremely proactive in the administration and follow up of the questionnaires.

Although the results of this study are interesting, there are several important limitations that should be considered when interpreting the data. First, this study was performed at a single site (Amman; the capital city of Jordan). Therefore, the results may not be representative of the views of pharmacists who work in urban areas outside of Amman. Moreover, the responses of pharmacists to the frequency of commonly dispensed vitamin types to various patient subgroups are entirely reflected by their knowledge and attitudes. This may deviate from the actual sales rate according to patients/consumers requests and personal choices. We acknowledge that this theme merits further large-scale investigation of population perspectives and awareness about the misuse of vitamins. Further evaluation on the impact of this survey towards increasing the awareness of pharmacists about the safety of vitamins is warranted.

Finally, although pharmacists in our community displayed positive beliefs in the usefulness of vitamins and their role in pharmaceutical care, further research is needed to extensively appraise their knowledge, attitudes and extent of awareness about other forms of CAM, for which pharmacists may play a crucial role in counselling society. 


\section{CONCLUSIONS}

In light of this study, it is clear that pharmacists in Jordan appear to have basic foundation knowledge about vitamins. However, Jordanian pharmacists are less aware about exact dosages, drug interactions, side effects and professional counselling on vitamin supplements using high quality literature sources. Overall, their current state of knowledge was less than optimal in meeting the patient demands for this area of healthcare. This result indicates a need for developing specific modules about complementary medicine, including vitamin and mineral supplementation, through pharmacy colleges as part of the curriculum for under-graduate pharmacy students. Further attempts should be pursued in developing regular refresher programmes on multivitamins for registered and practicing pharmacists. In conclusion, the Jordanian FDA must create regulations and laws to guarantee that most vitamin and mineral supplements are not defined as OTC products and, thus, should be regularly evaluated to ensure higher manufacturing and production standards.

\section{ACKNOWLEDGEMENTS}

The authors would like to thank the research assistants Amal Abu AL-Homos, Bashar Derbashi, Bahaa Reyda and Mona Ali Al-Maqademeh for helping with data collection, entry and analysis.

\section{CONFLICT OF INTEREST}

The author declares that they have no competing interests.

This research received no specific grant from any funding agency in the public, commercial or not-forprofit sectors.

\section{References}

1. Dugan BD. Enhancing community pharmacy through advanced pharmacy practice experiences. Am J Pharm Educ. 2006;70(1):21.

2. McGivney MS, Meyer SM, Duncan-Hewitt W, Hall DL, Goode JV, Smith RB.. Medication therapy management: Its relationship to patient counseling, disease management, and pharmaceutical care. J Am Pharm Assoc. 2007;47(5):620628.

3. Azhar S, Hassali MA, Ibrahim MI, Ahmad M, Masood I, Shafie AA.. The role of pharmacists in developing countries: The current scenario in Pakistan. Hum Resour Health. 2009;7:54.

4. The APhA Pharmaceutical Care Guidelines Advisory Committee, approved by the APhA Board of Trustees. Principles of Practice for Pharmaceutical Care. In: American Pharmacists Association, 1 August 1995. http://www.pharmacist.com (Accessed on 27 January, 2011).

5. Pilnick A. "Patient counselling" by pharmacists: four approaches to the delivery of counselling sequences and their interactional reception. Soc Sci Med. 2003;56(4):835-849.

6. Terrie YC. A pharmacist's guide to OTC therapy: Assisting patients in selecting multivitamins. In: Pharmacy Times, 1 August 2006. http://www.pharmacytimes.com (Accessed on 21 June 2010).

7. American Society of Health-System Pharmacists. ASHP guidelines on pharmacist-conducted patient education and counseling. Am J Health Syst Pharm. 1997;54(4):431-434

8. The National Council on Patient Information and education (NCPIE). Be MedWise campaign. http://www.bemedwise.org/about us/about us.htm (Accessed on 30 September, 2011).

9. Anonymous. Be MedWise campaign promotes safe OTC use. Pharmacy Today. 2003; 9(10):3.

10. Newton GD, Pray WS, Popovich NG. New OTC drugs and devices 2003: a selective review. J Am Pharm Assoc. 2004;44(2):211-225.

11. Farrell J, Ries NM, Boon $\mathrm{H}$. Pharmacists and natural health products: a systemic analysis of professional responsibilities in Canada. Pharm Pract (Internet). 2008 6(1):33-42.

12. Wall GC, Krypel LL, Miller MJ, Rees DM. A pilot study of complementary and alternative medicine use in patients with fibromyalgia syndrome. Pharm Pract (Internet). 2007;5(4):185-90.

13. Fries CJ. Classification of complementary and alternative medical practices. Family physicians' rating of effectiveness. Can Fam Physician. 2008;54(11):1570-1571.

14. Ernst E, Resch KL, Mills S, Hill R, Mitchell A, Willoughby M, White AR. Complementary medicine - a definition. Br J Gen Pract. 1995;45(398):506

15. Maha N, Shaw A. Academic doctors' views of complementary and alternative medicine (CAM) and its role within the NHS: an exploratory qualitative study. BMC Complement Altern Med. 2007;7:17.

16. Moore ML. Complementary and alternative therapies. J Perinat Educ. 2002;11(1):39-42.

17. US Food and Drug Administration. Overview of dietary supplements. Center for Food Safety and Applied Nutrition. http://www.cfsan.fda.gov/ dms/ds-overview.html (Accessed on 3 January, 2001).

18. Garrard J, Harms S, Eberly LE, Matiak A. Variations in product choices of frequently purchased herbs: caveat emptor. Arch Intern Med. 2003;163(19):2290-2295.

19. US Food and Drug Administration. Dietary supplement Alerts and Safety Information. In: Office of Dietary Supplements 6 October 2009. http://www.fda.gov/Food/Dietarysupplement/Alerts/default.htm (Accessed on 25 January, 2011).

20. The National Center of Complementary and Alternative Medicine. Alerts and Advisories. In: National Institutes of Health, 1 January 2010. http://nccam.nih.gov/news/alerts/ (Accessed on 5 July, 2010).

21. Wazaify M, Younes AA. Pharmacy in Jordan. Am J Health Syst Pharm. 2005;62(23):2548-2551. 
22. Lev E, Amar Z. Ethnopharmacological survey of traditional drugs sold in the Kingdom of Jordan. J Ethnopharmacol. 2002;82(2-3):131-145.

23. Jordanian Pharmaceutical Association. Good Pharmacy Practice. http://www.jpa.org.jo/index.php/cms/gpp (Accessed on 30 September, 2011).

24. Eisenberg DM, Davis RB, Ettner SL, Appel S, Wilkey S, Van Rompay M, Kessier RC. Trends in Alternative Medicine Use in the United States, 1990-1997. JAMA. 1998;280(18):1569-1575.

25. Kwan D, Hirschkorn K, Boon H. U.S. and Canadian pharmacists' attitudes, knowledge, and professional practice behavior toward dietary supplements: a systemic review. BMC Complement Altern Med. 2006;6:31.

26. Astin JA. Why patients use alternative medicine: Results of a national study. JAMA. 1998;279(19):1548-1553.

27. Ernst E. Complementary medicine: implications for informed consent in general practice. Br J Gen Pract. 2004;54(499):82-83.

28. Wazaify M, Younes AA, Abu-Gharbieh E, Tahaineh L. Societal perspectives on the role of community pharmacists and over-the-counter drugs in Jordan. Pharm World Sci. 2008;30(6):884-891.

29. Neuhouser ML, Wassertheil-Smoller S, Thomson C, Aragaki A, Anderson GL, Manson JE, Patterson RE, Rohan TE, van Horn L, Shikany JM, Thomas A, LaCroix A, Prentice RL. Multivitamin use and risk of cancer and cardiovascular disease in the Women's Health Initiative cohorts. Arch Intern Med. 2009;169(3):294-304.

30. de Gaetano G; Collaborative Group of the Primary Prevention Project. Low-dose aspirin and vitamin E in people at cardiovascular risk: a randomized trial in general practice. Lancet. 2001;357(9250):89-95.

31. Brown BG, Zhao XQ, Chait A, Fisher LD, Cheung MC, Morse JS, Dowdy AA, Marino EK, Bolson EL, Alaupovic P, Frohlich J, Albers JJ. Simvastatin and niacin, antioxidant vitamins, or the combination for the prevention of coronary disease. N Engl J Med. 2001;345(22):1583-1592.

32. Slatore CG, Littman AJ, Au DH, Satia JA, White E. Long-term use of supplemental multivitamins, vitamin C, vitamin E, and Folate does not reduce the risk of lung cancer. Am J Respir Crit Care Med. 2008;177(5):524-530.

33. Zhang SM, Cook NR, Albert CM, Gaziano JM, Buring JE, Manson JE. Effect of combined folic acid, vitamin B6, and vitamin B12 on cancer risk in women: a randomized trial. JAMA. 2008;300(17):2012-2021.

34. Bjelakovic G, Nikolova D, Gluud LL, Simonetti RG, Gluud C. Mortality in randomized trials of antioxidant supplements for primary and secondary prevention: systematic review and meta-analysis. JAMA. 2007;297(8):842-857.

35. Roswall N, Olsen A, Christensen J, Dragsted LO, Overvad K, Tjønneland A. Micronutrient intake and risk of colon and rectal cancer in a Danish cohort. Cancer Epidemiol. 2010;34(1):40-46.

36. Payne ME, Anderson JJ, Steffens DC.Calcium and vitamin D intakes may be positively associated with brain lesions in depressed and non-depressed elders. Nutr Res. 2008;28(5):285-292.

37. Kris-Etherton PM, Lichtenstein AH, Howard BV, Steinberg D, Witztum JL; Nutrition Committee of the American Heart Association Council on Nutrition, Physical Activity, and Metabolism. Antioxidant Vitamin Supplements and Cardiovascular Disease. Circulation. 2004;110(5):637-641.

38. United States Department of health and Human Services. National Institutes of Health (NIH). Women's Health Initiative (WHI) program. http://www.nhlbi.nih.gov/whi/background.htm (Accessed on 30 September, 2011).

39. Tiralongo E, Wallis M. Attitudes and perceptions of Australian pharmacy student towards complementary and alternative medicine - a pilot study. BMC Complement Altern Med. 2008;8:2.

40. Evans E, Evans J. Changes in pharmacy students' attitudes and perceptions toward complementary and alternative medicine after completion a required course. Am J Pharm Educ. 2006;70(5):105.

41. Harris IM, Kingston RL, Rodriguez R, Choudary V. Attitudes towards complementary and alternative medicine among pharmacy faculty and students. Am J Pharm Educ. 2006;70(6):129.

42. Dolder C, Lacro J, Dolder N, Gregory P. Pharmacists' use of and attitudes and beliefs about alternative medications. Am J Health Syst Pharm. 2003;60(13):1352-1357.

43. Fakeye TO, Onyemadu O. Evaluation of knowledge base of hospital pharmacists and physicians on herbal medicines in Southwestern Nigeria. Pharm Pract (Internet). 2008;6(2):88-92.

44. Wazaify M, Yousef AM, Al-Bakri AG, Bustanji Y. Self-medication patterns in Amman, Jordan. Pharm World Sci. 2008;30(1):24-30.

45. Abahussain NA, Abahussain EA, Al-Oumi FM. Pharmacists' attitudes and awareness towards the use and safety of herbs in Kuwait. Pharm Pract (Internet). 2007;5(3):125-129.

46. Government of Canada. Natural Health Products Regulations. In Canada Gazette Part II Volume 137. Issue 13 Her Majesty the Queen in Right of Canada; 2003.

47. Williamson EM. Drug interactions between herbal and prescription medicines. Drug Saf. 2003;26(15):1075-1092.

48. Brown CM. Use of alternative therapies and their impact on compliance: perceptions of community pharmacists in Texas. J Am Pharm Assoc. 1998;38(5):603-608 